\title{
Labour Market Decisions of Australian Families Coping with Mental and Physical Disabilities
}

\author{
Nerina Vecchio \\ Griffith Business School, \\ Griffith University Gold Coast Campus, \\ PMB 50 Gold Coast Mail Centre Queensland 9726 Australia \\ n.vecchio@griffith.edu.au
}




\title{
Labour Market Decisions of Australian Families Coping with Mental and Physical Disabilities
}

\begin{abstract}
This paper examines the labour market decisions of family members of individuals afflicted with a disability. The analysis, based on data collected in the Survey of Disability, Ageing and Carers 2003, is confined to family members of working age, residing with a person of disability. The investigation segregates by disability (mental and physical), reflecting different resource requirements. The presence of a mentally disabled family member increased the value of unpaid work of others in the home and reduced their propensity to participate in the labour force. Of families afflicted with a mental disability, females were less likely to participate in the labour force compared to females in other families. Male members of families afflicted with a mental disability were likely to withdraw from the labour market when receiving a government transfer payment - possibly reflecting the limited care resources within these families.
\end{abstract}

JEL: I190; J140; J170; J200; J220 


\section{INTRODUCTION}

This paper examines the labour market decisions of family members residing with individuals afflicted with a disability. The deinstitutionalisation of the mental health system in Australia and the subsequent concerns by health professionals and communities about the inequitable access of formal support services for families afflicted with a mental illness provides the impetus for this research. An understanding of the opportunity cost of caring at home in terms of forgone employment will assist policy-makers when allocating scarce health resources.

In an ageing Australian population the challenge for economists is the deployment of scare health resources to the best possible effect. One recent remedy has been the deinstitutionalisation of the health system, a shift in care from large-scale residential facilities to community-based living arrangements. Implemented since the 1980s, deinstitutionalisation is driven by its cost-effectiveness to the government (Onyx and Bradfield, 1991; Healy, 2002) and the idea that the normalisation of the living environment is conducive to the development of the individual's capacity. The Australian government's emphasis on home-based care has led to the informal care (i.e. unpaid care and support) by family and friends becoming an increasingly important source of support to disabled Australians (Kendig, McVicar and Reynolds, 1992; Beilhorz, Considine and Watts, 1992; Courtney, Minichiello and Waite, 1997; Victorian Parliament, 1997; Queensland Health, 2004). In 1992, the Australian National Mental Health Policy extended the deinstitutionalisation process by moving the focus of care of people afflicted with a mental illness from hospitals to the community.

Little is known about labour market decisions of family members living with people experiencing disabilities and few empirical studies focus on issues of mental health. 
Traditionally, cost-of-illness studies assist in estimating the impact of disease on the labour supply of the afflicted individual (Loprest, Rupp and Sandell, 1995; Ettner, 1996b; Lim, Sanderson and Andrews, 2000). In recent years such studies have expanded to consider the cost to the primary carer, typically involving an investigation of the female labour supply (Berger and Fleisher, 1984; Wolf and Soldo, 1994; Carmichael and Charles, 1998; Pezzin and Schone, 1999; Spiess and Schneider, 2003; Carmichael and Charles, 2003; Henz, 2004). Others have extended this research to include the labour supply decisions of other family members (Roberts, 1999). Labour force participation studies often use probit analysis that controls for variables (such as education, age, number of children, gender, work experience, urban, other sources of income) that affect labour force behaviour (Berger and Fleisher, 1984; Ettner, 1996a; Carmichael and Charles, 1998; Wolf and Soldo, 1994; Roberts, 1999; O’Hara, 2004; Sanders, 1990).

Investigating the role of a husband's poor health on the wife's labour force participation decision, O’Hara (2004) concluded that the wife was 8\% more likely to work, when the husband's health deteriorated from excellent to poor. A similar study that investigated married women's allocation of time to employment and care of elderly parents revealed little evidence of a reduced propensity to be employed or reduction in the hours of work (Wolf and Soldo 1994). Among the European countries, reported differences in the changing work hours associated with movement into care suggest a substitution effect for institutional and formal home care (Spiess and Schneider, 2003). A possible explanation for these inconsistent findings is the impact of government welfare payments (Berger and Fleisher, 1984). The more generous the payment, the greater the likelihood of a reduction in the labour supply, and the more time devoted to the role of primary carer. 
Acknowledging that nowadays women are more likely to participate in the paid workforce and significantly contribute to family finances, more recent studies consider the less traditional role of men as informal carers. Using data from the 1987 National Survey of Families and Households, Ettner (1996a) found that in providing care to parents the effect of care-giving on work hours was greater for women than for men. Carmichael and Charles (2003) identified a direct negative relationship between caring commitment and participation for female though not male carers. This supports their previous findings that caring may both constrain female labour supply and reduce earnings (Carmichael and Charles 1998). A longitudinal study ${ }^{1}$, using data sourced from Great Britain 1994-95 Family and Working Lives Survey, found no significant difference in the number of years provided in informal care between men and women (Henz, 2004). Lower paid and part-time workers, typically dominated by female labour, reported the strongest link to care-giving (Henz, 2004).

Roberts (1999) extended the cost-of-illness research to include not only the primary carer but also other family members. In the United States, adult males were found to increase their probability of labour force participation in the presence of mental illness in the family when mental illness was accompanied by a chronic physical illness. There was no impact on the female's probability of labour force participation when a family member was afflicted with a mental illness. When the mentally ill family member was afflicted with additional illnesses hours of work reduced for both female and male other family members (Roberts, 1999).

\footnotetext{
${ }^{1}$ Repeatedly observing subjects over time.
} 
Previous studies concerning illness and its impact on labour supply suffer from several limitations. Many of these studies have been confined to specific populations of both caregivers and receivers. Consideration is often limited to one family member, generally a female. And since samples include only the caregivers, results often suffer from selection bias. Also, studies using data sourced from regional rather than national surveys cannot be generally applied for policy analysis (Roberts, 1999). A further limitation of previous studies is the neglect of disability type in the analysis of data.

Although studies often ignore disability type, compared to people with a physical disability, those with a mental disability require a different set of services to allow them to participate in the community and conduct activities of daily living (Williams and Doessel, 2001). The duties of informal carers can involve behavioural management issues, and time devoted to making decisions in relation to daily living and to liaising with the legal and criminal justice systems. In 2001 approximately 9.6\% of the Australian population reported having a long-term mental ${ }^{2}$ or behavioural problem that lasted or was expected to last for six months (ABS, 2003b). Given the differences in resource requirements between those carers of people experiencing a mental versus a physical disability, it is appropriate to investigate labour market decisions of family members segregated by disability type.

Based on the data collected from the Australian Survey of Disability, Ageing and Carers (ABS, 2003d), the investigation reported here examines the labour market participation of family members of working age, who reside with non-institutionalised individuals

\footnotetext{
${ }^{2}$ A mental illness significantly interferes with a person's thinking, limiting their ability to achieve goals, cope with the normal stresses of life and work productively (Mental Health Council of Australia, 2004). Common mental illnesses and disorders include depression, anxiety, substance use disorders, eating disorders, psychosis and dementia (Mental Health Council of Australia, 2004).
} 
diagnosed with a disabling condition, either mental or physical. Given the national policy emphases towards home-based care and claims of inadequate access of services for people afflicted with a mental illness residing in the community (MHCA and CAA, 2000; Groom, Hickie and Devenport, 2003), an investigation into the labour market decisions of family members is timely.

The paper is organised as follows. Section 2 discusses the theoretical model. Section 3 presents the research method, followed by the empirical results in Section 4. Lastly the conclusions and limitations of this study are discussed in Section 5.

\section{THEORETICAL MODEL}

Extending Becker's theory of time allocation, it is hypothesized that higher wages generate a shift away from time-intensive towards earning-intensive services. Government transfer payments such as government pensions, allowances or other benefits lead to the substitution of paid work for unpaid service provision within the household by the family member. Considering that care as a commodity is produced at the home, the question becomes how does the presence of an ill family member affect the labour supply of other family members?

Subject to time and budget constraints, an individual's utility function is maximized when the optimal demand for time-intensive versus earning-intensive commodities are achieved. According to Roberts (1999), the presence of an ill family member raises the productivity of those engaged in household production with a greater amount of time devoted to care-giving, a reduction in leisure time and an ambiguous effect on labour market time. 
Several investigations have drawn attention to resource inadequacies in the wider community for people with a mental illness (Mental Health Council of Australia, 2000; Lamb and Bachrach, 2001; Groom et al., 2003; Palmer, 2005). In particular the Not-forService report (Mental Health Council of Australia, 2005) highlighted the issue of inadequate access to high quality health services for individuals afflicted with a mental illness and the burden of care placed on family members. This leads to the assumption that family members of those afflicted with a mental disability place greater value on their unpaid labour within the home. Previous studies (Berger and Fleisher, 1984; Spiess and Schneider, 2003) also linked higher government transfer payments with lower labour force participation. In the present study, it is hypothesized that:

1. Family members residing with individuals afflicted with a mental disability are less likely to participate in the labour force compared to family members residing with individuals afflicted with a physical disability.

2. Receipt of government transfer payments is more likely to decrease the labour force participation rate of family members residing with individuals afflicted with a mental disability compared to family members residing with individuals afflicted with a physical disability.

In this study, disability is categorised into two main disabling conditions, mental and physical. Mental and behavioural disorders listed by the ABS (2003c, p. 30) include psychoses and mood effective disorders (dementia and alzheimers, depression and mood affective disorders), neuroses, stress-related and somatoform disorders (nervous tension and stress), and intellectual and developmental disorders. A person is considered to have a disability if they possess a limitation, restriction or impairment, which lasts at least six months and restricts everyday activities (ABS, 2003c, p. 72). 


\section{RESEARCH METHOD}

All family members are included in a general model. This allows an adjustment of each family member's participation in the labour market. Using probit analysis, estimates are obtained of the effect of disability type on the probability of labour force participation.

\subsection{Data Description}

The data for analysis were sourced from the Australian Survey of Disability, Ageing and Carers (SDAC), Confidential Unit Record Files (CURFs) (ABS, 2003d). The survey, conducted throughout Australia by trained interviewers in 2003, covered people in both urban and rural areas and in all states and territories. Every member of the selected households was included in the survey irrespective of disability status, age and carer-status (ABS, 2003a).

The data in the database generated by the SDAC were collected from a sample of 36,088 individuals and person level weights were available to extend the sample to represent the entire Australian civilian non-institutionalized population. After excluding individuals who did not fit either the study's criteria of the working population or the family profile, 2,583 cases remained. To estimate the impact of an individual afflicted with a disability on the labour supply decisions of other family members, the analysis was confined to those family members between 20 and 64 years in age, without a disability, residing with families of two or more persons. Since there may be several families residing in the one household or more than one family member with a disability, to simplify the analysis only those households with one family residing with one disabled person were chosen. For weighting purposes, the 2003 SDAC data were benchmarked to the estimated population as at 30 June 2003, based on results from the 2001 Census of Population and Housing. 
Using the SPSS statistical package the data were screened prior to analysis. The results of the analysis revealed more than $5 \%$ of cases with missing values for the variable household income. A Missing Value Analysis also revealed systematic differences in person characteristics between cases with missing values and cases without missing values. Because the amount and pattern of missing data can bias results (Tabachnick and Fidell 1996, p. 60), the household income variable was excluded from the analysis. The descriptive statistics also reported highly uneven splits among several variables. Rummel (1970) suggests deleting dichotomous variables with 90-10 splits between categories (cited in Tabachnick and Fidell 1996, p. 66). To overcome the problems associated with outliers, the tweleve dichotomous variables representing each educational level were grouped and converted into three dichotomous variables with more even spits, HIGHSCH, DIPCERT, TERTY. The categories representing marital status, were grouped and converted to the dichotomous variable, MARRIED and not married, the latter including separated, widowed, divorced, never married.

\subsection{Empirical Model}

The model consists of the labour force participation (LFP) as the dependent variable and the explanatory variables defined in Table 1. The model also includes control variables identified as important in previous labour force participation studies.

$$
\begin{aligned}
& \text { LFP }=\alpha+\beta_{1}(\text { AGE })_{i}+\beta_{2}(\text { AGESQ })_{i}+\beta_{3}(\text { CITY })_{i}+\beta_{4}(\text { MARRIED })_{i}+\beta_{5}(G T b)_{i}+\beta_{6}(\text { COB })_{i}+\beta_{7} \\
& (\text { FEMALE })_{i}+\beta_{8}(\text { HIGHSCH })_{i}+\beta_{9}(\text { DIPCERT })_{i}+\beta_{10}(\text { TERTY })_{i}+\beta_{11}(\text { KIDSU5 })_{i}+\beta_{12}(\text { NbrFAM })_{i}+ \\
& \beta_{13}(\text { LMTFAM })_{i}+\beta_{14}(\text { MIFAM })_{i}+\beta_{15}(\text { MILIMIT })_{i}+\beta_{16}(\text { MIFAMxGTb })_{i}+\varepsilon
\end{aligned}
$$


The dependent variable, LFP, represents those in the selected sample aged between 20 and 65 who are either in the labour force - that is, employed or actively seeking employment - or those not in the labour force. A person is considered employed if they have worked in a job, business or farm during the reference week (the full week prior to the date of interview) (ABS 2003c, p. 73).

The explanatory variables MIFAM indicate the presence of a family member who is either mentally or physically disabled. GTb, also a dichotomous variable, indicates whether government transfer payments are received. The sign and the magnitude of the estimate of MIFAM and the interaction term MIFAM x GTb both indicate the impact of a mentally ill family member on the labour force supply of other family members, ceribus paribus. In line with previous studies (Wolf and Soldo, 1994; Carmichael and Charles, 1998; Roberts, 1999), the model includes AGESQ, the squared value of the $\mathrm{i}^{\text {th }}$ person's age. Including AGESQ best captures the effect of age on LFP. The disability variables MIFAM and MILIMIT are constructed from the two main disabling conditions, mental and physical. The mental and physical categories are derived from the main disabling conditions reported by the Australian Bureau of Statistics (ABS 2003c, p. 30). LMTFAM takes the value of 1 if a disabled family member has a profound to moderate core activity limitation and 0 if a disabled family member has a mild core activity limitation or schooling/employment limitation.

The model excludes several variables reported by Roberts (1999) that may affect the labour force participation of family members residing with a person afflicted with a disability. For instance, data limitations did not permit the construction of the variable 
that captures work restriction associated with ill-health ${ }^{3}$. In addition, variables that capture information about the existence of multiple mental and physical illnesses could not be constructed from the SDAC data set.

\section{EMPIRICAL RESULTS}

In this section the characteristics of the family members are presented, followed by a discussion of the results from the analysis and the estimates obtained from segregating the data by gender.

\subsection{Descriptive statistics}

A statistical summary of the weighted population is presented in Table 2. The characteristics of the family members residing with a person of disability are segregated by labour force status - those participating in the labour force $(\mathrm{N}=1,098,165)$ and those not in the labour force $(\mathrm{N}=314,687)$. As expected a greater proportion of family members participate in the labour force if they are either male, single or do not reside with children under five years of age. Fewer participate in the labour force if they reside with a family member who possesses a profound to moderate core limitation. Referring to Table 2, workforce participation increases with higher levels of education. The age categories also reflect the expected labour force patterns during the lifecycle.

\section{INSERT TABLE 2 HERE}

\footnotetext{
${ }^{3}$ A similar variable WKLIMIT (1 if limited in kind of work or regular activities as a result of physical health in the last four weeks; 0 otherwise) was constructed from the SDAC data. Dichotomous variables with very uneven splits between two categories produce outliers (Tabachnick and Fidell 1996 p66). The 0.08\% (limited in kind of work or regular activities) and 99.02\% (otherwise) split of the WKLIMIT led to the omission of this variable from the analysis.
} 
Among family members participating in the workforce, little difference exists between the proportion residing with those diagnosed with either a mental $(76.3 \%)$ or physical condition (78\%). There is, however, less participation among family members who reside in households when the mentally ill person possesses a profound to moderate limitation (72.4\%), compared to others (78.3\%).

\subsection{Labour Force Participation Model}

The estimated coefficients and standard errors of the parameters are presented in Table 3. A statistically significant difference exists between the fitted model and the observed frequencies ${ }^{4}$. In addition to the probit regression, a logit regression using the same model (not reported here) was run. Comparing the logit and probit estimates produced similar results. A logit estimate of a parameter multiplied by 0.625 gives an adequate approximation of the probit estimate of the same parameter (Gujarati, 1995, p. 569).

In Table 3, a positive (negative) sign on the coefficient of an explanatory variable indicates that higher (lower) values of the variable are associated with an increase (decrease) in a family member participating in the labour force. Most of the estimates for the control variables - the coefficients for AGE, AGESQ, NbrFAM, KIDSU5, LMTFAM, MARRIED, FEMALE, COB, HIGHSCH, DIPCERT, TERTY, GTb - are statistically significant $(\mathrm{p}<0.001)$ and have the expected signs.

\section{INSERT TABLE 3 HERE}

\footnotetext{
${ }^{4}$ Tabachnick and Fidell (1996, p. 597) note that with a very large sample size, almost any difference between models is likely to be reliable.
} 
The negative relationship between LFP and the disability type variable MIFAM supports the first hypothesis. It is implied that care-taking responsibilities for a mentally ill family member draws particular individuals out of the labour force, possibly reflecting the increased value of individuals as carers within these households compared to other households. The positive coefficient for MILIMIT is unexpected and indicates that the presence of a mentally ill family member with a profound to moderate core limitation increases the probability of other members participating in the labour force.

The high correlation between household income and receipt of a government pension $\left(0.384^{5}\right.$ correlation is significant at the 0.01 , two tailed level), led to the later becoming a proxy for household income. The positive interaction coefficient, MIFAMxGTb, reveals a link between the receipt of a government transfer payment by those residing with a mentally ill family member, and participation in the labour force. This association is confirmed by fitting a second model that uses 'Employment Status' as the dependent variable. This analysis reveals a positive and significant association between receipt of government benefits by families afflicted with a mental disability and being employed.

\subsection{Segregating the Data by Gender}

The unexpected signs of several coefficients in the full model may be due to the opposing effects for males and females. Empirical research demonstrates that males and females possess different elasticities in their supply of labour. After segregating the data by gender the model was re-estimated to further identify the relationship. The gender models reported in Table 3 support previous research (Roberts, 1999; Carmichael and

\footnotetext{
${ }^{5}$ When a continuous variable and a dichotomous variable are strongly correlated in the population, the highest correlation that can be obtained is well below 1 (Tabachnick and Fidell 1996, p. 59).
} 
Charles, 2003). Being married and having young children reduce women's labour supply. For men, being married increases their labour participation.

The analysis of the disability type variables also reveals opposing effects between males and females. In contrast to males, MIFAM has a negative impact on female labour supply. That is, female members of families afflicted with a mental illness are less likely to participate in the labour force. The coefficient for the MILIMIT variable also reveals that families afflicted with a mental illness of profound to moderate core limitation reduce female labour force participation. For male members of families afflicted with a mental illness, the labour force participation is positive.

A difference exists between physically and mentally afflicted families. Referring to the results from the female segregated model, the negative MIFAM indicates that female members of families afflicted with a mental disability are less likely to participate in the labour force compared to female members of families afflicted with a physical disability. Furthermore, female members of families with a mentally ill person with profound to moderate core limitation (MILIMIT) tend to not enter the labour force compared to other females.

Estimating separate models for each gender also clarifies the interaction term. The coefficient, MIFAMxGTb, indicates that among families afflicted with a mental illness, males receiving a government transfer payment are less likely to participate in the labour force. It seems that males substitute labour force participation for informal work within the home. Since this group is not in the labour force it is receiving forms of benefits other than unemployment-related benefits. Possibly greater value is placed on informal care within these households. In contrast, coefficient estimates of the model 
based on the female data shows that among families afflicted with a mental disability, labour force participation is positive for recipients of government transfer payments. This suggests that there is less of a substitution effect between workforce participation and care duties at home among female than male family members. Indeed, several Australian studies note little evidence of a reduction in care of older people corresponding to the trend of middle-aged women returning to the workforce (Chappell 1990, p. 445; Howe and Sargeant 1999). The increase in casual and part-time employment has provided greater opportunities for female family members to combine paid employment with informal home-care. The dominance of women in the part-time workforce, accounting for $71 \%$ of part-time workers in Australia (ABS, 2005), explains women's ability to better absorb the hours of informal care. An additional regression model that uses employment status as the dependent variable supports this proposition ${ }^{6}$.

\footnotetext{
${ }^{6}$ The female regression model revealed that among families afflicted with a mental disability, employed females tended to receive a government benefit. In contrast, a separate regression model for the male data revealed that among families afflicted with a mental disability, unemployed males tended to receive a government benefit.
} 


\section{CONCLUSION}

This study examined the labour market decisions of family members of working age, who resided with individuals diagnosed with a disability. Based on the Survey of Disability, Ageing and Carers, a probit analysis provided estimates of the impact of disability type, mental or physical, on the probability of labour force participation. The data, segregated by gender, neutralized the potential problem of the offsetting impacts for females and males.

Responding to the problem of scarcity within the health system, the Australian government's deinstitutionalisation process has given rise to criticism regarding the lack of support services to those afflicted with a mental disability. This research supports the claim of inadequate resources directed towards mental health. Results indicate that the disability type of a family member is important in determining the probability of labour force participation. The probit regression analysis supports the hypothesis that the presence of a mentally ill family member increased the value of others in the home and reduced their propensity to participate in the labour force.

By segregating the model by gender it was found that female members of families afflicted with a mental disability were less likely to participate in the labour force compared to female members of families afflicted with a physical disability. The segregated models also revealed several variables with opposing impacts for males and females. In contrast to males, female labour supply was constrained within families afflicted with a mental disability. Also, male members receiving a government transfer payment appeared less likely to enter the labour force, possibly reflecting the greater value placed on informal care within these households. 
The positive relationship between women's participation in the labour market and government transfer payments reflects the increase in casual and part-time employment since the 1980s. Further research will be undertaken to test this assumption.

Limitations of this study included data restrictions that did not allow the inclusion of some relevant independent variables into the model. In particular, a variable that records the proportion of income contributed by other family members could not be constructed. Also, the study excluded families suffering an illness with no associated disability. Only those families with one individual afflicted with a disability were investigated. The disability variables used in the model were based on the main disabling condition rather than all the individual's diagnosed conditions. Also, this study did not investigate the support provided by government (other than government transfer payments), charity and volunteer groups.

\section{REFERENCES}

Australian Bureau of Statistics (2005), Year Book Australia. Catalogue Number, 1301.0, Australian Bureau of Statistics, Canberra.

Australian Bureau of Statistics (2003a), Information Paper. Basic Confidentialised Unit Record File. Survey of Disability, Ageing and Carers, Catalogue Number 4430.0.00.001, Australian Bureau of Statistics, Canberra.

Australian Bureau of Statistics (2003b), National Health Survey: Mental Health, Catalogue Number 4811.0, Australian Bureau of Statistics, Canberra. 
Australian Bureau of Statistics (2003c), Disability, Ageing and Carers: Summary of Findings, Catalogue Number 4430.0, Australian Bureau of Statistics, Canberra.

Australian Bureau of Statistics (2003d), Basic Confidentialised Unit Record File. Survey of Disability, Ageing and Carers, Australian Bureau of Statistics, Canberra.

Beilharz, P., Considine, M. and Watts, R. (1992), Arguing About the Welfare State: The Australian Experience, Allen and Unwin, Sydney.

Berger, M. and Fleisher, B. (1984), ‘Husband’s Health, Wife’s Labour Supply’, Journal of Health Economics, vol.3, Issue 3, pp.62-75.

Carmichael, F. and Charles, S. (2003), 'The Opportunity Costs for Informal Care: Does Gender Matter?’, Journal of Health Economics, vol.22, Issue 6, pp.781-803.

Carmichael, F. and Charles, S. (1998), 'The Labour Market Costs of Community Care’, Journal of Health Economics, vol.17, Issue 6, pp.747-765.

Courtney, M., Minichiello, V. and Waite, H. (1997), 'Aged care in Australia: A critical review of the reforms', Journal of Aging Studies, vol.1, no.30, pp.229.

Ettner, S. (1996a), 'The Opportunity Cost of Elder Care', The Journal of Human Resources, vol.31, pp.189-205.

Ettner, S. (1996b), 'New Evidence on the Relationship Between Income and Health', Journal of Health Economics, vol.15, pp.67-85. 
Groom, G., Hickie, I., and Devenport, T. (2003), Out of Hospital, Out of Mind! A report detailing mental health services in Australia in 2002 and community priorities for national mental health policy 2003-2008, Mental Health Council of Australia, Canberra.

Gujarati D (1995), Basic Econometrics, Third Edition. McGraw-Hill, New York.

Healy, J. (2002), 'The Care of Older People: Australia and the United Kingdom', Social Policy and Administration, vol.36, no.1, pp.1-19.

Henz, U. (2004), 'The Effects of Informal Care on Paid-work Participation in Great Britain: A Lifecourse Perspective', Ageing and Society, vol.24, pp. 851-880.

Kendig, H., McVicar, G. and Reynolds, A. (1992), The Victorian Linkages Evaluation. Department of health, housing and community services and community services, Melbourne.

Lamb, R., and Bachrach, L. (2001), 'Some perspectives on deinstitutionalization', Psychiatric Services, vol.52, pp.1039-1045.

Lim, D., Sanderson, K. and Andrews, G. (2000), 'Lost Productivity Among Full-Time Workers with Mental Disorders', The Journal of Mental Health Policy and Economics, vol.3, pp.139-146. 
Loprest, P., Rupp, K. and Sandell, S. (1995), 'Gender, Disabilities and Employment in the Health and Retirement Study', The Journal of Human Resources, vol.30, pp.s293s311.

Mental Health Council of Australia (2005), Not For Service: Experiences of Injustice and Despair in Mental Health Care in Australia, Mental Health Council of Australia, Canberra.

Mental Health Council of Australia (2000), Carers of People with Mental Illness Project, Mental Health Council of Australia, Canberra.

Mental Health Council of Australia (2004), 'Fact sheet', available at http://www.health.gov.au/hsdd/mentalhe/resources/reports/cpmip.htm. Cited on the 6th of October, 2004.

O’Hara, B. (2004), 'Do Mothers Work to Support Ailing Husbands?', Journal of Family and Economic Issues, vol.25, p. 2.

Onyx, B. and Bradfield, B. (1991), 'Community Development and Government Response’, Community Development Journal, vol.26-27, pp.166-174.

Rummel, J (1970), ‘Applied Factor Analysis’ in Tabachnick, B. and Fidell, L., Using Multivariate Statistics. Third Edition. HarperCollins, Northridge.

Palmer, M. (2005), Inquiry into the Circumstances of the Immigration Detention of Cornelia Rau, Attorney General’s Department, Commonwealth of Australia, Canberra. 
Pezzin, L. and Schone, B. (1999), 'Intergenerational Household Formation, Female Labour Supply and Informal Caregiving: A bargaining Approach', Journal of Human Resources, vol.34, no.3, pp. 475-490.

Roberts, A. (1999), 'The Labour Market Consequences of Family Illness', The Journal of Mental Health Policy and Economics, vol.2, pp.183-195.

Sanders, J. (1990), 'Public transfers: Safety net or inducement into poverty?', Social Forces, 68, pp.813-834.

Spiess, C. and Schneider, A. (2003), 'Interactions between Care-giving and Paid Work Hours Among European Midlife Women, 1994 to 1996’, Ageing and Society, vol.23, pp.41-68.

Tabachnick, B. and Fidell, L. (1996), Using Multivariate Statistics. Third Edition. HarperCollins, Northridge.

Victorian Parliament (1997), Inquiry into Planning for Positive Ageing, Family Community Development Committee, Victorian Government, Melbourne.

Williams, R. and Doessel, D. (2001), The Economics of Mental Health Care. Industry, Government and Community Issues, Ashgate, Aldershot.

Wolf , D. and Soldo, B. (1994), ‘Married women’s allocation of time to employment and care of elderly parents', The Journal of Human Resources, vol.29, no.4, pp.12591276. 
Queensland Health (2004), Queensland Health Home and Community Care Program, State Plan 2003-2004, Queensland Health, Brisbane.

\section{ACKNOWLEDGEMENTS}

The author would like to thank George Tawadros (Griffith University) and Christine Smith (Griffith University) for their helpful suggestions. 
Table 1. Variable definitions and weighted descriptive statistics

\begin{tabular}{|c|c|c|c|}
\hline Variable & Definition & Mean & $\begin{array}{l}\text { Std } \\
\text { Devn }\end{array}$ \\
\hline \multicolumn{4}{|c|}{ Labour force Variables } \\
\hline LFP & $\begin{array}{l}1 \text { if labour force participant (employed/unemployed); } 0 \\
\text { otherwise. }\end{array}$ & 0.777 & 0.42 \\
\hline \multicolumn{4}{|c|}{ Sociodemographic Variables } \\
\hline $\mathrm{AGE}^{7}$ & Age in mean ranges divided by $100:(0.22$ to 0.62$)$ & 0.412 & 0.13 \\
\hline FEMALE & 1 if female; 0 otherwise. & 0.523 & 0.50 \\
\hline COB & 1 if country of birth is non English speaking; 0 otherwise & 0.162 & 0.37 \\
\hline CITY & 1 if major city; 0 otherwise. & 0.670 & 0.47 \\
\hline GTb & 1 if government benefit received; 0 otherwise. & 0.158 & 0.37 \\
\hline \multicolumn{4}{|c|}{ Time cost variables } \\
\hline MARRIED & 1 if married; 0 otherwise & 0.629 & 0.48 \\
\hline KIDSU5 & 1 if dependent child under 5 in the family; 0 otherwise. & 0.157 & 0.36 \\
\hline NbrFAM & Number of persons in family (2-8) & 3.423 & 1.21 \\
\hline LMTFAM & $\begin{array}{l}\text { Family member's disability limitation: } 1 \text { if profound to } \\
\text { moderate core activity; } 0 \text { if mild or schooling/employment. }\end{array}$ & 0.447 & 0.50 \\
\hline \multicolumn{4}{|c|}{ Human capital variables } \\
\hline HIGHSCH & 1 if 12 years of schooling; 0 otherwise & 0.179 & 0.39 \\
\hline TERTY & 1 if Post or Bachelor Graduate; 0 otherwise. & 0.176 & 0.38 \\
\hline DIPCERT & 1 if Diploma Certificate; 0 otherwise. & 0.309 & 0.46 \\
\hline \multicolumn{4}{|c|}{ Mental illness variables } \\
\hline MIFAM & $\begin{array}{l}\text { Main disabling condition of family member: } 1 \text { if mental; } 0 \text { if } \\
\text { physical. }\end{array}$ & 0.175 & 0.38 \\
\hline MILIMIT & $\begin{array}{l}1 \text { if mentally ill family member has profound to moderate } \\
\text { core limitation; } 0 \text { otherwise. }\end{array}$ & 0.091 & 0.29 \\
\hline
\end{tabular}

\footnotetext{
${ }^{7}$ SDAC (2003) records the age of the respondents in five year class intervals from 20 to 65 . A new continuous variable was created using the one mean for each class interval.
} 
Table 2. Characteristics of Family Members of Working Age Residing with a

Person of Disability by Labour Force Status, Australia, 2003

\begin{tabular}{|c|c|c|c|c|c|}
\hline \multicolumn{2}{|l|}{ Characteristics of Family Members } & \multirow{2}{*}{$\begin{array}{r}\begin{array}{r}\text { Not in } \\
\text { labour } \\
\text { force }\end{array} \\
\text { Row \% }\end{array}$} & \multirow{2}{*}{$\begin{array}{r}\begin{array}{r}\text { Labour } \\
\text { force } \\
\text { participant }\end{array} \\
\text { Row } \%\end{array}$} & \multicolumn{2}{|c|}{ Total } \\
\hline & & & & Cat \% & Count \\
\hline \multirow[t]{2}{*}{ Gender } & Male & $7.8 \%$ & $92.2 \%$ & $47.8 \%$ & 674656 \\
\hline & Female & $35.5 \%$ & $64.5 \%$ & $52.2 \%$ & 738195 \\
\hline \multirow[t]{2}{*}{ Country of birth } & ish speaking & $19.8 \%$ & $80.2 \%$ & $83.8 \%$ & 1183989 \\
\hline & ish speaking & $35.1 \%$ & $64.9 \%$ & $16.2 \%$ & 228862 \\
\hline \multirow[t]{2}{*}{ Residing in a major City } & No & $25.0 \%$ & $75.0 \%$ & $33.0 \%$ & 466645 \\
\hline & Yes & $20.9 \%$ & $79.1 \%$ & $67.0 \%$ & 946206 \\
\hline \multirow[t]{2}{*}{ Government pension/allow/benefit } & No & $14.6 \%$ & $85.4 \%$ & $84.2 \%$ & 1189225 \\
\hline & Yes & $63.1 \%$ & $36.9 \%$ & $15.8 \%$ & 223627 \\
\hline \multirow[t]{2}{*}{ Registered marital status } & Single & $16.8 \%$ & $83.2 \%$ & $37.1 \%$ & 524441 \\
\hline & Married & $25.5 \%$ & $74.5 \%$ & $62.9 \%$ & 888411 \\
\hline \multirow[t]{2}{*}{ Kids under 5 present in family } & No & $20.4 \%$ & $79.6 \%$ & $84.3 \%$ & 1190465 \\
\hline & Yes & $32.6 \%$ & $67.4 \%$ & $15.7 \%$ & 222387 \\
\hline \multirow[t]{5}{*}{ Number of persons in family } & 2 & $30.8 \%$ & $69.2 \%$ & $29.4 \%$ & 415448 \\
\hline & 3 & $18.0 \%$ & $82.0 \%$ & $23.3 \%$ & 329402 \\
\hline & 4 & $14.6 \%$ & $85.4 \%$ & $28.7 \%$ & 404834 \\
\hline & 5 & $23.3 \%$ & $76.7 \%$ & $13.8 \%$ & 195673 \\
\hline & $6 \geq$ & $33.8 \%$ & $66.2 \%$ & $4.8 \%$ & 67495 \\
\hline \multirow[t]{3}{*}{ Educational attainment } & High school & $19.5 \%$ & $80.5 \%$ & $17.9 \%$ & 251281 \\
\hline & na/certificate & $15.5 \%$ & $84.5 \%$ & $30.9 \%$ & 435018 \\
\hline & Tertiary & $14.2 \%$ & $85.8 \%$ & $17.6 \%$ & 248156 \\
\hline \multirow[t]{9}{*}{ Age in years } & $20-24$ & $12.3 \%$ & $87.7 \%$ & $13.9 \%$ & 195983 \\
\hline & $25-29$ & $16.5 \%$ & $83.5 \%$ & $9.5 \%$ & 133770 \\
\hline & $30-34$ & $21.1 \%$ & $78.9 \%$ & $9.8 \%$ & 138367 \\
\hline & 35-39 & $21.3 \%$ & $78.7 \%$ & $12.5 \%$ & 176361 \\
\hline & $40-44$ & $18.1 \%$ & $81.9 \%$ & $12.3 \%$ & 173754 \\
\hline & $45-49$ & $13.3 \%$ & $86.7 \%$ & $11.8 \%$ & 166134 \\
\hline & $50-54$ & $21.5 \%$ & $78.5 \%$ & $11.7 \%$ & 164976 \\
\hline & $55-59$ & $38.2 \%$ & $61.8 \%$ & $10.8 \%$ & 152187 \\
\hline & $60-64$ & $49.1 \%$ & $50.9 \%$ & $7.9 \%$ & 111320 \\
\hline \multirow{2}{*}{$\begin{array}{l}\text { Limitation: person of } \\
\text { disability }\end{array}$} & ng, employ’t & $19.8 \%$ & $80.2 \%$ & $55.4 \%$ & 782014 \\
\hline & to moderate & $25.3 \%$ & $74.7 \%$ & $44.6 \%$ & 630837 \\
\hline \multirow[t]{2}{*}{ Main condition: person of disability } & Physical & $22.0 \%$ & $78.0 \%$ & $82.5 \%$ & 1166075 \\
\hline & Mental & $23.7 \%$ & $76.3 \%$ & $17.5 \%$ & 246777 \\
\hline \multicolumn{2}{|c|}{ Limitation: person of mental disability Otherwise } & $21.7 \%$ & $78.3 \%$ & $90.9 \%$ & 1284507 \\
\hline \multicolumn{2}{|c|}{ Profound to moderate } & $27.6 \%$ & $72.4 \%$ & $9.1 \%$ & 128345 \\
\hline
\end{tabular}


Table 3. Regression Analysis Results, weighted

\begin{tabular}{lllllll}
\hline Variable & Male & \multicolumn{3}{c}{ Female } & Total & \\
& Coefficient & Std. & Coefficient & Std. & Coefficient & $\begin{array}{l}\text { Std. } \\
\text { error }\end{array}$ \\
CONSTANT & $-1.899^{*}$ & 0.034 & $-0.279^{*}$ & 0.022 & $-1.156^{*}$ & 0.018 \\
AGE & $1.265^{*}$ & 0.161 & $7.722^{*}$ & 0.112 & $6.615^{*}$ & 0.089 \\
AGESQ & $-5.741^{*}$ & 0.189 & $-12.053^{*}$ & 0.132 & $-10.855^{*}$ & 0.105 \\
COB & $-0.325^{*}$ & 0.007 & $-0.407^{*}$ & 0.004 & $-0.371^{*}$ & 0.004 \\
CITY & 0.000 & 0.006 & $0.006^{*}$ & 0.004 & $0.015^{*}$ & 0.003 \\
MARRIED & $0.580^{*}$ & 0.007 & $-0.148^{*}$ & 0.004 & $0.052^{*}$ & 0.004 \\
KIDSU5 & $-0.240^{*}$ & 0.011 & $-1.052^{*}$ & 0.005 & $-0.858^{*}$ & 0.004 \\
NbrFAM & $0.089^{*}$ & 0.003 & $-0.040^{*}$ & 0.002 & $-0.050^{*}$ & 0.001 \\
LMTFAM & $-0.115^{*}$ & 0.006 & $-0.121^{*}$ & 0.004 & $-0.064^{*}$ & 0.007 \\
HIGHSCH & $-0.200^{*}$ & 0.008 & $0.343^{*}$ & 0.005 & $0.191^{*}$ & 0.004 \\
DIPCERT & $-0.016^{*}$ & 0.007 & $0.451^{*}$ & 0.004 & $0.350^{*}$ & 0.004 \\
TERTY & $-0.033^{*}$ & 0.009 & $0.646^{*}$ & 0.005 & $0.465^{*}$ & 0.004 \\
GTb & $-1.323^{*}$ & 0.007 & $-1.233^{*}$ & 0.005 & $-1.262^{*}$ & 0.004 \\
FEMALE & & & & & $-0.988^{*}$ & 0.003 \\
MIFAM & $.085^{*}$ & 0.012 & $-0.127^{*}$ & 0.006 & $-0.097^{*}$ & 0.005 \\
MILIMIT & $0.462^{*}$ & 0.018 & $-0.030^{*}$ & 0.009 & $0.103^{*}$ & 0.007 \\
MIFAMxGTb & $-0.742^{*}$ & 0.018 & $0.396^{*}$ & 0.011 & $0.119^{*}$ & 0.009 \\
& & & & & & \\
R ${ }^{2}$ & $0.339^{*}$ & & $0.368^{*}$ & & $0.424^{*}$ & \\
Log Likelihood & 210344.5 & & 548542.3 & & 803302.6 & \\
\hline
\end{tabular}

Note: * Significant at $<0.001$ level 